\title{
The Virtual Driving Coach - design and preliminary testing of a predictive eco-driving assistance system for heavy-duty vehicles
}

\author{
Daniel Heyes $^{1}$ - Thomas J. Daun ${ }^{2}$ - Andreas Zimmermann ${ }^{1}$ • Markus Lienkamp ${ }^{2}$
}

Received: 26 December 2014 / Accepted: 9 July 2015 /Published online: 23 July 2015

(C) The Author(s) 2015. This article is published with open access at SpringerLink.com

\begin{abstract}
Purpose The commercial vehicle sector is characterized by high competitive pressure. Fuel consumption is one major factor that influences the transport efficiency and competitiveness of logistics companies. Therefore, an eco-driving assistance system (EDAS) is developed in order to support the driver in sustainably maintaining an efficient driving stylethe Virtual Driving Coach (ViDCo). In this paper, we describe the design and development process of ViDCo as well as results of the first steps of evaluation and preliminary testing. Methods An EDAS is developed that uses knowledge of infrastructure based on digital maps in order to proactively and predictively provide the driver with driving advice. The system's algorithms are structured within the modules "situation detection", "driving error detection", and "message filtering and prioritization". The evaluation of ViDCo comprises preliminary field-testing on public roads as well as a driving simulator experiment.

Results Driving tests show that the Virtual Driving Coach is capable of enhancing fuel efficiency for commercial vehicles in real-world scenarios. The results of the driving simulator experiment indicate a positive level of user acceptance and system safety. Furthermore, the results point towards a
\end{abstract}

Daniel Heyes

daniel.heyes@man.eu

Thomas J. Daun

daun@ftm.mw.tum.de

1 MAN Truck \& Bus AG, Dachauer Straße. 667, 80995 Munich, Germany

2 Institute of Automotive Technology, Technische Universität München, Boltzmannstr. 15, 85748 Garching, Germany positive correlation between user acceptance and the subjects' judgment of learning.

Conclusions The Virtual Driving Coach's concept is a promising approach for efficient and environmentally friendly road transport.

Keywords Eco-driving · Driver assistance system · Fuel efficiency $\cdot$ Prediction · Driving simulator experiment · User acceptance $\cdot$ System safety $\cdot$ Judgment of learning

\section{Introduction}

Rising fuel costs have become a major cost driver for logistics companies and contribute to nearly $30 \%$ of Germany's long distance transportation costs (Fig. 1).

Commercial vehicle manufacturers have been able to achieve significant savings by modifying vehicle designs and improving engine efficiency $[1$, p. 4]. Despite these efforts, the driver's driving style still has a significant impact on fuel consumption.

From fuel efficiency training programs it is a well-known fact that truck drivers can reduce fuel consumption and component wear. Geiler [2] found short-term fuel savings of about $7 \%$ through driver training, which deteriorated to $4 \%$ within 10 months. In a study conducted by Wahlberg [3] regarding eco-driving training, professional drivers reduced their fuel consumption by $6 \%$ in the short term. Again, long-term savings weakened to $2 \%$.

For commercial vehicles, eco-driving assistance systems (EDAS) are available that analyze driving behavior and provide continuous feedback on driving style [5-7]. This therefore helps to remind the drivers of the importance of fuelefficient driving. The driver, however, has to anticipate the fuel-efficient driving strategy by himself. 


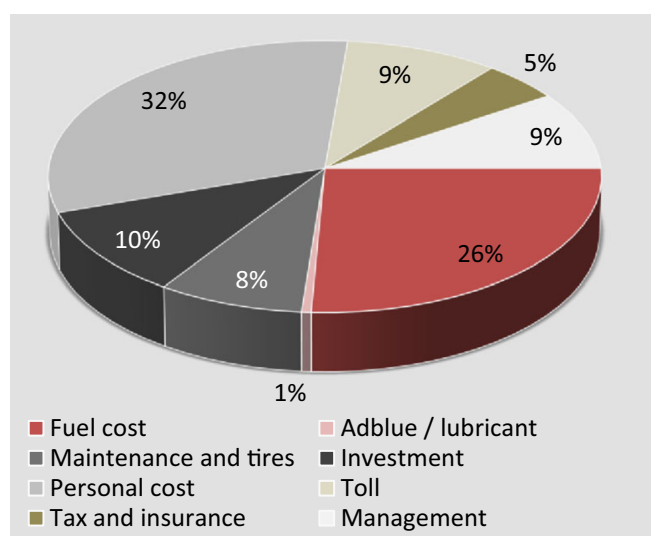

Fig. 1 Cost structure of long-haul trucks (according to [4])

Information about preceding driving situations are provided for EDAS of passenger vehicles [8-10]. Haptic feedback on the acceleration pedal or a message on the display informs the driver when to release the accelerator pedal in front of speed-reducing infrastructure elements.

Still there is a lack of eco-driving assistance systems that give the driver specific, situational driving advice about fuelefficient and wear-reducing actions while at the same time taking the unique requirements of commercial vehicles into account. It can be assumed that predictive driving advice may also increase acceptance.

In this paper, we describe the design of an EDAS for heavy commercial vehicles - the Virtual Driving Coach (Ger. Virtueller Fahrtrainer; ViDCo) - which is capable of detecting sub-optimal driving behavior in a situation-specific manner and for some scenarios also predictively (Section 5). If ViDCo detects a state of sub-optimal driving, it outputs an advisory message to the driver by means of a message on a display unit and a synthesized voice message. Since the Virtual Driving Coach continuously monitors and supports drivers during their transport assignments, this mode of assistance may be called system-based on-the-job training.

Moreover, we present results of ViDCo's evaluation process (Section 6). The EDAS's evaluation was done by means of extensive field testing and a driving simulator experiment. The methods of the driving simulator experiment and the results of the objective measures have been reported by Daun et al. in [11]. As the results of the questionnaires have not been reported so far, we present the according results with regard to the self-reported evaluation of user acceptance, system safety and judgment of learning.

\section{System description}

According to literature on eco-driving with respect to heavy commercial vehicles, drivers have numerous possibilities to influence fuel consumption and component wear [12-14]. In order to select situations and scenarios in which the Virtual Driving Coach should support the driver with advisory messages, a detailed analysis based on expert investigations and literature review is performed. This analysis reveals over 150 different situations $[15,16]$. But not every driving error in those situations results in significant increased fuel consumption or component wear. By an expert rating, the situations are prioritized according to their influence on eco-driving. Additionally it is rated how an eco-support system is capable of detecting those situations and to which extent driving advice is suitable to support the driver. As a result, 14 relevant situations with respect to eco-driving are identified and the corresponding driving advice is implemented in ViDCo (Table 1). The advisory messages of these situations can be classified into driving style, anticipatory driving, operational level and usage of manual gearbox.

- Driving style: A key factor for fuel efficient driving is to maintain a uniform speed profile. This can be achieved by reducing the maximum speed on motorways, the usage of cruise control and by keeping an appropriate headway distance to preceding vehicles.

- Anticipatory driving: By an early reaction to topography, infrastructure and slow preceding vehicles, less energy is wasted through the braking system. Thus, the driver is supported proactively and predictively to determine the optimal time at which the vehicle can be operated in coasting mode without infringing acceptance thresholds.

- Operational level: Operating the vehicle in an appropriate manner helps to reduce fuel consumption and component

Table 1 Overview of relevant driving advice regarding eco-driving

\begin{tabular}{|c|c|}
\hline Category & Driving advice \\
\hline \multirow[t]{3}{*}{ Driving style } & Reduce travel speed to $\max .85 \mathrm{~km} / \mathrm{h}$ \\
\hline & $\begin{array}{l}\text { Maintain sufficient headway distance } \\
\text { to preceding vehicles }\end{array}$ \\
\hline & $\begin{array}{l}\text { Maintain uniform velocity by using cruise } \\
\text { control and speed limiter }\end{array}$ \\
\hline \multirow[t]{3}{*}{ Anticipatory driving } & Coast before crests in time \\
\hline & $\begin{array}{l}\text { Coast before infrastructural objects in time (speed } \\
\text { limits, bends, roundabouts, highway exits) }\end{array}$ \\
\hline & Coast before slow preceding vehicles \\
\hline \multirow[t]{4}{*}{ Operational level } & Avoid kick down \\
\hline & Accelerate at high engine torques \\
\hline & Decelerate using wear-free braking systems \\
\hline & Stall engine at long idling phases \\
\hline \multirow{4}{*}{$\begin{array}{l}\text { Usage of manual } \\
\text { gearbox }\end{array}$} & Use high gears while cruising at constant speed \\
\hline & Use low starting gear \\
\hline & Handle clutch pedal correctly \\
\hline & Do not use accelerator pedal until clutch is closed \\
\hline
\end{tabular}


wear. The engine efficiency can be increased by accelerating at high engine torque. Unnecessary downshifts, e.g. by triggering the kick down switch, should be avoided. Switching off the engine reduces fuel consumption during long idling phases. Brake wear is reduced by applying wear-free braking systems, such as retarder or exhaust brake.

- Usage of manual gearbox: Clutch wear is reduced by choosing a low starting gear and a correct handling of the clutch pedal. When cruising, the vehicle should be operated at a high gear.

\subsection{Modules of the system}

The algorithms of the Virtual Driving Coach consist of the modules situation detection, driving error detection and message filtering and prioritization (Fig. 2). The situation detection module interprets the situational context the vehicle is in, while the driving error detection module identifies suboptimal driving behavior and decides whether driving advice is advisable. Downstream, the message filtering and prioritization module guarantees sufficient time between advisory messages to achieve a high level of user acceptance.

\subsubsection{Situation detection}

In the context of driving, Fastenmeier defines the term situation as the environment of the driver-vehicle's human-machine system from the driver's perspective whereby situations are delimitable units in space, time and their characteristics [17, p. 27f].

This concept is illustrated by an example: Exceeding $85 \mathrm{~km} / \mathrm{h}$ permanently increases fuel consumption excessively while hardly saving time due to traffic effects $[18,19]$. The situation where excessive velocity is not recommended can be described using the situational variables street type (highway), topography (even) and driver intention (not overtaking).

This ensures that a driving error is only triggered in obviously inefficient situations, whereas the driver is given the opportunity to fully exploit the properties of the vehicle in

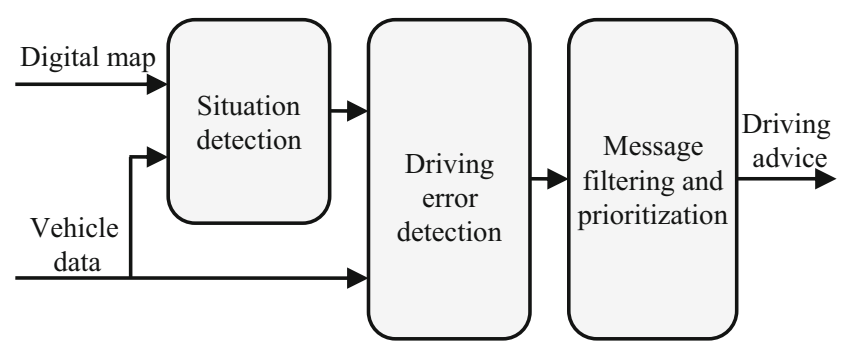

Fig. 2 Layout of the Virtual Driving Coach with the modules "situation detection", "driving error detection", "message filtering and prioritization" topographically challenging terrain or when overtaking. If all the situational variables meet the required properties, the situation "excessive speed" is active and driving advice can be given if the driver operates the vehicle in an inadequate way.

The situational variables are derived by a systematic approach $[15,16]$. Starting point is a test drive over $400 \mathrm{~km}$ on a commonly used test track for commercial vehicles [20], which is divided by experts into situations relevant for eco-driving. By analyzing situations relevant for fuel consumption, situational variables are discovered and divided into discrete states. An algorithmic description of the situational variables is formulated and the measurement data of the test drive is analyzed. For every situation relevant for fuel consumption, all occurring combinations of the situational variables are obtained. These combinations of the situational variables eventually define the situations which are detected by the situation detection module.

For the analysis of the current driving situation, it suffices to determine the situational variables at the very moment in time. However, anticipatory situation detection has to predict the future deployment of the situational variables in order to ascertain when a situation starts.

The eco-driving assistance system supports the driver in finding the optimum point in time to decelerate the vehicle by releasing the accelerator pedal. For this purpose, the velocity of the coasting vehicle has to be predicted.

Huber [21] proposes to predict the vehicle speed for the road segments ahead cyclically with a model of the longitudinal dynamics and to use this to determine the coasting phases. Assuming the vehicle is operated in coasting mode, the velocity $v$ of the vehicle can be calculated with a simplified longitudinal dynamics model $[22,23]$.

$$
\left(m+m_{e q}\right) \dot{v}=\frac{i M_{e n g}}{r}-m g(a+\mu)-w v^{2}
$$

$$
\begin{array}{ll}
m & \text { Vehicle mass in } \mathrm{kg} \\
m_{e q} & \text { Equivalent mass of rotating parts in } \mathrm{kg} \\
i & \text { Gear ratio including final drive } \\
M_{\text {eng }} & \text { Engine's drag torque in } \mathrm{Nm} \\
r & \text { Dynamic rolling radius of the tire in } \mathrm{m} \\
g & \text { Gravitational constant }(\approx 9.81 \mathrm{~m} / \mathrm{s}) \\
a & \text { Slope } \\
\mu & \text { Coefficient of friction } \\
w & \text { Air resistant coefficient in } \mathrm{kg} / \mathrm{m}
\end{array}
$$

By means of the relationship

$$
\dot{v}=\frac{d v}{d x} v
$$


the equation of the longitudinal dynamics (1) can be expressed as

$$
\left(m+m_{e q}\right) \frac{d v}{d x}=\frac{i M_{\text {eng }}}{r v(x)}-\frac{1}{v(x)} m g(a(x)+\mu)-w v(x)
$$

depending on the distance $x$ on the path in front of the vehicle.

If the predicted velocity $v(x)$ exceeds a pre-calculated maximum velocity $v_{\max }(x)$ the vehicle will reach a critical velocity at which a brake intervention is likely even in coasting mode. Thus the maximum velocity $v_{\max }(x)$ is defined as the maximum velocity a driver will accept without braking, and is calculated as a function of infrastructure elements lying ahead, such as speed limits, curve radii, turning angles at crossings, and street types.

The mere reaction to the maximum velocity would indeed reduce the fuel consumption most effectively, but may slow the vehicle down unacceptably during the coasting phase. If, for example, the speed limitation is situated in a long downhill slope the vehicle passes the beginning of the downhill slope very slowly. This driving strategy would both increase the driving time and interfere with the traffic behind. Therefore a driving advice is only given if the predicted velocity $v(x)$ always exceeds minimum velocity $v_{\min }(x)$. This minimum velocity profile mainly depends on the road type. Only a short distance before the vehicle is expected to pass a speed limit, the minimum velocity is adapted to the maximum velocity (Fig. 3).

Furthermore, an advisory message will only be given if the drop in velocity during the coasting phase is significant. This avoids driving advice which would lead to only small fuel savings while putting the driver's acceptance at risk.

\subsubsection{Driving error detection}

For every situation relevant for eco-driving, an optimal driving strategy is defined. If driving behavior differs in a given

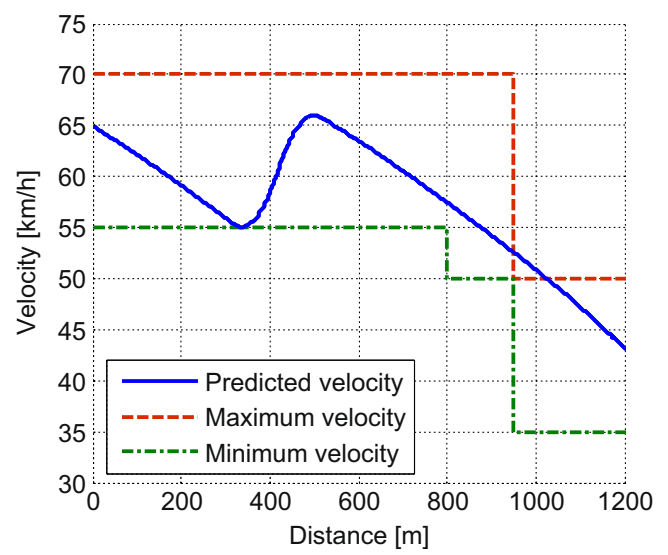

Fig. 3 Detection of a coasting situation. The predicted velocity exceeds the maximum velocity without dropping below the minimum velocity. The beginning of a coasting phase is detected in this manner. situation from this optimal strategy, a driving error is transmitted to the filtering and prioritization module.

ViDCo's driving errors and the corresponding advisory messages are categorized. Two categories of driving errors are specifically important with regard to processing in the algorithms: the type of driving error and the time-wise detectability.

The type of driving error draws a distinction between strategic and tactical driving errors. Strategic errors occur with regard to choices and decisions about the mode of operation (e.g., choice of travel speed, use of longitudinal control systems). They often persist for a long period of time. Even though their impact on fuel consumption is rather small in the short term, they reduce fuel efficiency markedly when persisting in the long term.

Tactical driving errors, on the other hand, are typically committed during transitions of driving state (e.g., acceleration, deceleration). In contrast to strategic errors, tactical driving errors are of a rather short-term nature. Since their influence on instantaneous fuel efficiency is high, tactical driving errors should be corrected immediately.

Tactical driving errors can further be classified into tacticalpredictive and tactical-retrospective driving errors. While tactical-retrospective errors are not connected to any specific event, tactical-predictive errors are related to infrastructure objects (e.g., speed limits, downhill gradient). Therefore, retrospective advice can only be given after the occurrence of the error, whereas predictive advisory messages are capable of correcting the driver's misbehavior in the process of conducting the error.

Separating situation detection and driving error detection enhances the robustness of the systems since driving errors can only be detected during a given situation. On the other hand, positive driver behavior can be identified if a situation occurs but no driving error is detected. Therefore driving performance can be assessed independently of the route by evaluating the ratio of driving errors with respect to the corresponding situations which have occurred.

\subsubsection{Message filtering and prioritization}

It is generally accepted that humans' cognitive capacities for processing information are limited, which is expressed in several theories (for an overview see e.g. [24, p. 12ff] and [25]). In the context of driving, the primary task itself may be highly demanding depending on aspects such as traffic, weather, and road conditions. In this regard, in-vehicle information systems (IVIS) and advanced driver assistance systems (ADAS) require additional resources from the drivers' mental or cognitive workload [26].

Without any kind of filtering module, the Virtual Driving Coach would issue an advisory message via the display unit for each and every detected state of suboptimal driving. If a 
driver causes several such detections within a short period of time, she or he would be confronted with numerous messages. In order to keep the information flow from the EDAS to the driver within acceptable limits, a filtering and prioritization module (FPM) is developed. A limitation of additional mental workload is expected to have a positive impact on three aspects which therefore act as distinctive design objectives during the development process of the filtering and prioritization module (FPM): system safety, user acceptance, and system impact on learning.

Advanced driver assistance systems (ADAS) or in-vehicle information systems (IVIS) "should enhance or at least not reduce road safety" [27, p. 206]. System safety is therefore a fundamental design objective in the development process of the Virtual Driving Coach (see also [27, 28]). Furthermore, ViDCo is capable of exploiting its potential only if the driver is willing to use the system. Dillon \& Morris define user acceptance as "the demonstrable willingness within a user group to employ information technology for the tasks it [the information technology] is designed to support" [29, p. 5]. Since the two objectives system safety and user acceptance are eminent for the safe and effective operation of the EDAS, they are classified as primary design objectives of the FPM.

ViDCo issues advisory messages to the driver only when his operating behavior deviates from optimum behavior. An optimum driver would not receive any system messages at all. This strategy of fostering learning is called negative reinforcement in the theory of operant conditioning [30]. As this concept of imparting knowledge does neither aim nor expect the driver to intentionally produce advisory messages and thus to learn actively, it may be concluded that ViDCo aims on inducing knowledge implicitly to the driver [31, p. 49].

Thus, the ultimate design goal for the Virtual Driving Coach would be to be capable of making any driver fully adopt the system's driving advice and eventually drive optimally. Without demanding to achieve this ultimate design goal, the FPM therefore should support the driver's process of adopting and learning to drive more efficiently. This objective of a positive system impact on learning is classified as a secondary design objective.

In order to achieve the three design objectives system safety, user acceptance, and system impact on learning, the algorithms of the FPM decide on the following tasks: which advisory message should when be transmitted, for how long, how often, and by which mode (visual or auditory)? The FPM consists of the three submodules prioritization, filtering, and output and timing (Fig. 4). In addition, it features a data memory.

For a description of the FPM's working principals, let us consider the general case of multiple detected and hence active driving errors. The logics of the FPM can best be understood by starting with the functionalities of the output and timing module.

Even if multiple driving errors are detected, the output and timing module issues a single message exclusively to the output unit. On the transmission of a newly detected driving error, a synthesized voice message informs the driver and an advisory message is displayed for a minimum period of time.

Due to the characteristics of the different categories of driving errors (Subsection 5.1.2), the output and timing module handles the minimum period of time as follows:

- If only a single strategic driving error is active, it will be displayed until the driver adapts the driving advice (e.g., reduces travel speed to $\max .85 \mathrm{~km} / \mathrm{h}$ ).

- Tactical-retrospective errors are displayed for at least $10 \mathrm{~s}$ (a period of $10 \mathrm{~s}$ is implied by van der Voort [32, p. 81] and was adopted after positive initial testing).

- Tactical-prospective driving errors are issued until the infrastructure object is passed through (e.g., beginning of speed limit).

Additionally, the output and timing module will initiate the repeated transmission of the synthesized voice message if a single strategic driving error is detected continually. This is meant to regain the driver's attention and to draw it back to the

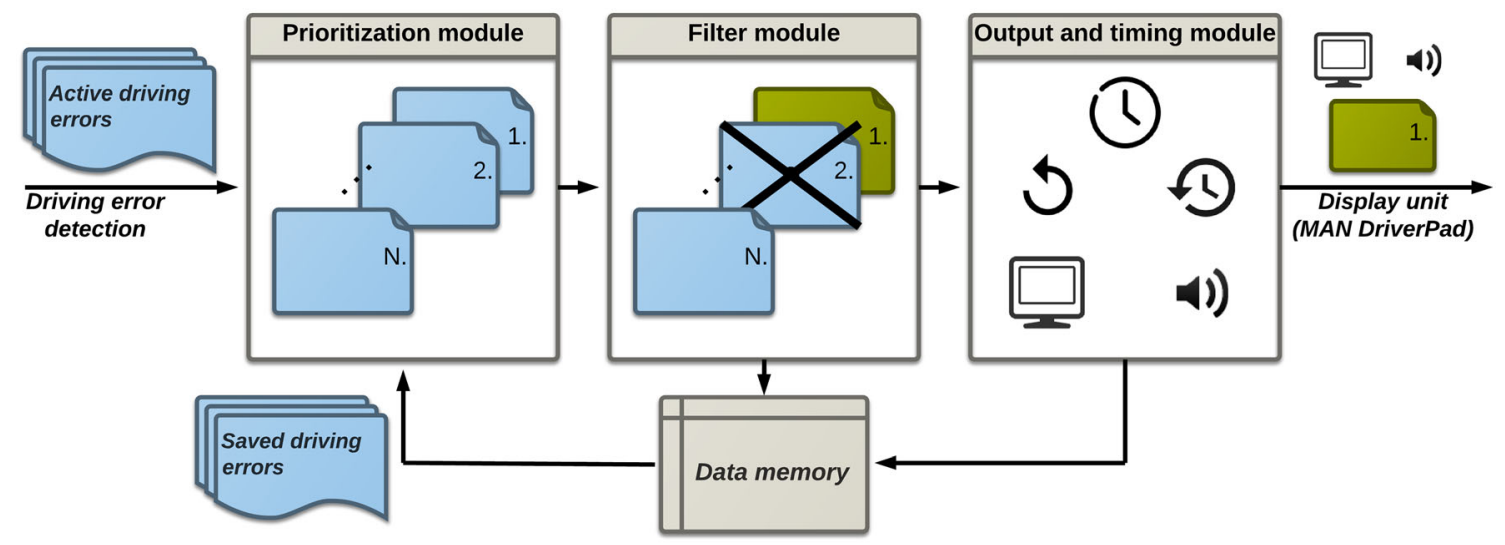

Fig. 4 Submodules of the filtering and prioritization module (FPM) 
display unit. In order to retain a high level of user acceptance, intervals between repeated transmissions are expanded. In the context of learning this strategy is called expanded retrieval [33] and is thus also implemented to support the driver's process of learning.

The filter module ensures only a single driving error is forwarded to the output and timing module. The filter blocks driving errors regardless of the priority assigned by the prioritization module. In general, blocked errors are saved in the data memory. The data memory thus enables the FPM to issue advisory messages even though the error was committed in the past and is not active anymore. However, a delayed submission makes only sense within a restricted time period after the detection. The filtering therefore also eliminates errors which are considered inactive for too long without writing these to the data memory.

Furthermore, the module detects and filters refusal by the driver. If a specific advisory message is ignored repeatedly, it must be assumed that the driver is not willing to follow this kind of driving advice. Therefore, this advisory message will be blocked and not be displayed on the current trip anymore.

The priority of the driving errors is determined dynamically by the prioritization module. It receives active errors from the driving error detection and reads saved ones from the data memory. An algorithm assigns a rating score to each error. The higher the score, the higher the priority of the error. The rating score consists of a constant term, which is specific for each driving error, and a dynamic term. While the constant term reflects the importance of the driving error with regard to its influence on fuel consumption as well as its criticality regarding a transmission in a timely manner, the dynamic term of the score will increase over time. The dynamic rating of a saved driving error is set to an even higher score, when its status changes from active to inactive (i.e., the very same error is not detected by the driving error detection anymore). By doing so, newly inactive, saved errors are handled with a higher priority in comparison to active driving errors and are thus more likely to be issued to the driver before expiration. Only after the advisory message of a corresponding driving error has been submitted to the display unit or the error has been considered inactive for too long, the driving error is removed from the data memory. As a result, the rating score is reset to its constant value.

\section{Evaluation and testing}

For the development of ADAS an iterative development process has been established [34, p. 30]: In an initial step the technical feasibility has to be proven, before, in a second step, human factors have to be considered. Finally, a proof of concept ensures the practical suitability of the advanced driver assistance system.
In this paper, we present results of the first two phases of the evaluation process of the Virtual Driving Coach. First, we introduce the procedure and results of a real-world field test. Afterwards, we describe the methods and results of surveys which were conducted during a driving simulator experiment [11].

\subsection{Real-world field test}

Real world driving situations are complex and can hardly be covered solely by a driving simulator experiment. A realworld field test can prove the technical feasibility of the Virtual Driving Coach and forms the basis for the following stages of the development process. The objective is thus to evaluate the technical feasibility of detecting consumptionrelevant driving situations in real-world scenarios without compromising drivability. This ensures a version of the EDAS is examined at the subsequent driving simulator experiment which is characterized by a practicable design. Therefore, ViDCo is integrated into a test vehicle and tested on public roads.

\subsubsection{Vehicle and test track}

The eco-driving assistance system is integrated into the tractor (MAN TGX, $P_{\max }=324 \mathrm{~kW}$ ) of a tractor-trailer combination (Fig. 5) as such a combination is commonly used for long-haul transport in Germany [35, p. 24]. The tractor is equipped with an adaptive cruise control system based on a radar sensor and an automatic gearshift system. Therefore no driving advice for manual gearbox is issued. In order to intensify the system response, the trailer is equipped with additional weight to achieve a gross vehicle weight of $40 \mathrm{t}$.

Information about infrastructure elements, slope gradient and curvature are obtained from a digital map using commercially available software (ADASRP: Advanced Driver Assistance System Research Platform). Via a GPS sensor, the vehicle position is matched on the map and the relevant map data

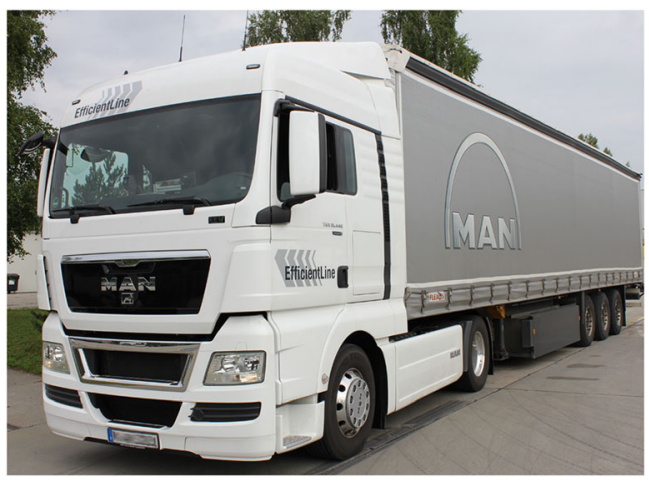

Fig. 5 Experimental vehicle 
in the vicinity of the vehicle is transmitted to a prototype control unit as Electronic Horizon [36, 37] (Fig. 6).

A high-accuracy fuel consumption measurement system is used for system evaluation. All data, including fuel flow rate, vehicle states, internal states of the prototype control unit and the GPS-position, are recorded synchronously and combined with a video image of the driving environment.

Using the vehicle data along with the vehicle's states and the driver's input, the prototype control unit performs the calculation of ViDCo's modules and triggers the output of driving advice on the display unit (Fig. 7).

The Virtual Driving Coach is evaluated on a demanding test track consisting of almost equal parts of highway and overland driving with an overall length of about $95 \mathrm{~km}$ (Fig. 8). The test track is driven six times by expert drivers to validate the functions of ViDCo.

\subsubsection{Results}

Altogether 205 advisory messages are issued on the six trips on the test track; on average 48 advisory messages per trip, which translates to one piece of driving advice per $2 \mathrm{~km}$.

Driving style has been influenced by advising reduced travel speed and the usage of cruise control and speed limiter. This resulted in a sufficient headway distance to preceding vehicles (Table 2).

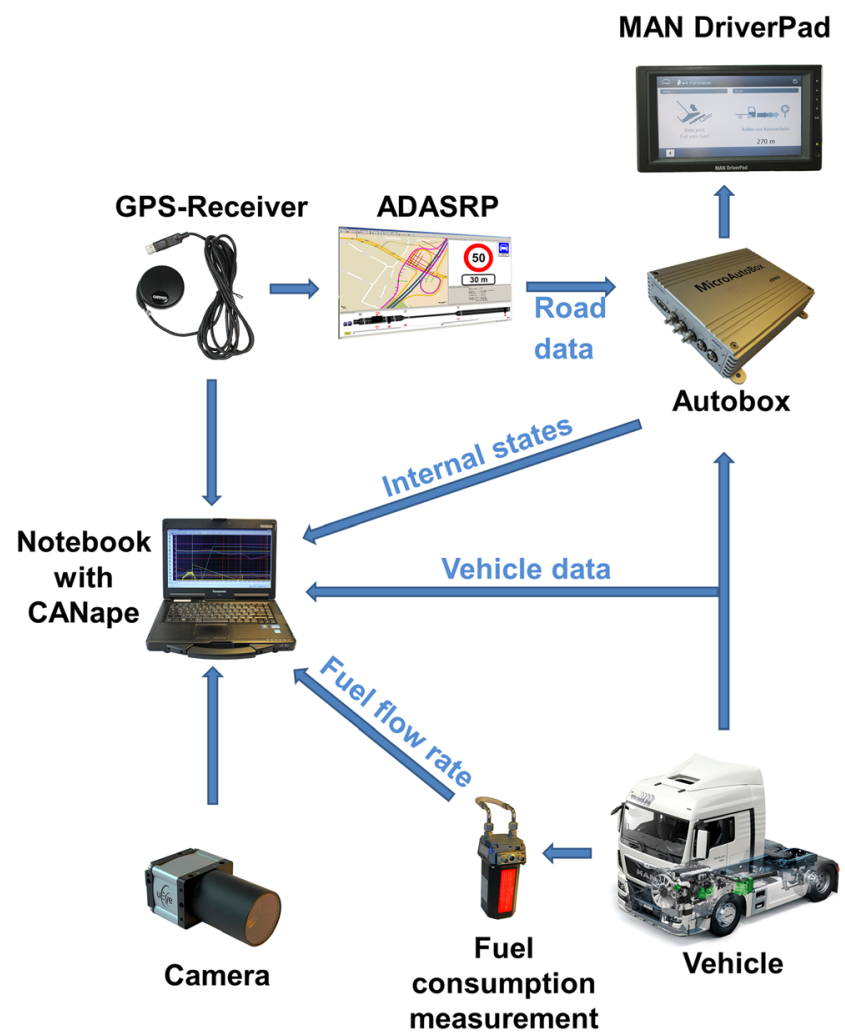

Fig. 6 System setup including data recording

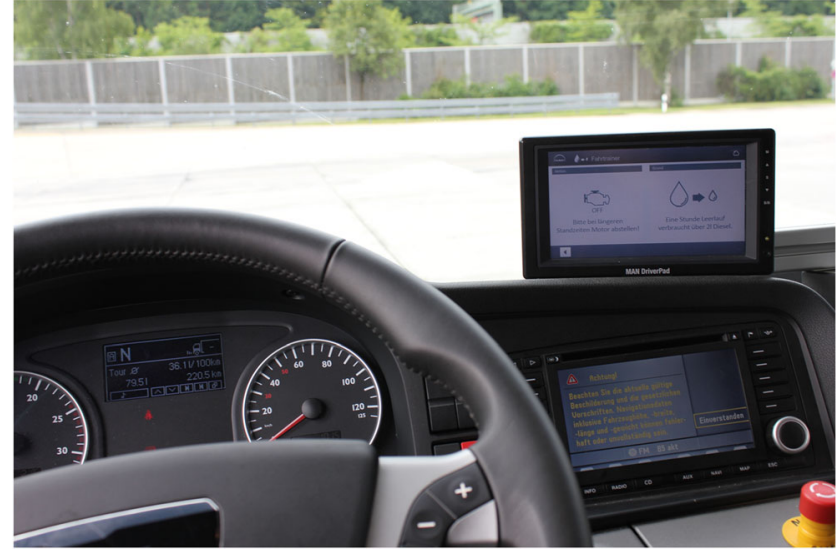

Fig. 7 Display unit of the Virtual Driving Coach in the vehicle

At operational level, each single piece of driving advice is issued (Table 3). Most advisory messages addressed insufficient usage of the wear-free braking system.

On average, 17 advisory messages are displayed for anticipatory driving, leading to a coasting length of $11.1 \mathrm{~km}$ (11.7 \% of total test track length). Speed limits contribute a major share to the coasting length with $5.4 \mathrm{~km}$ (Fig. 9).

No driving advice for coasting before a slow preceding vehicle is issued. It could be assumed that improved driving

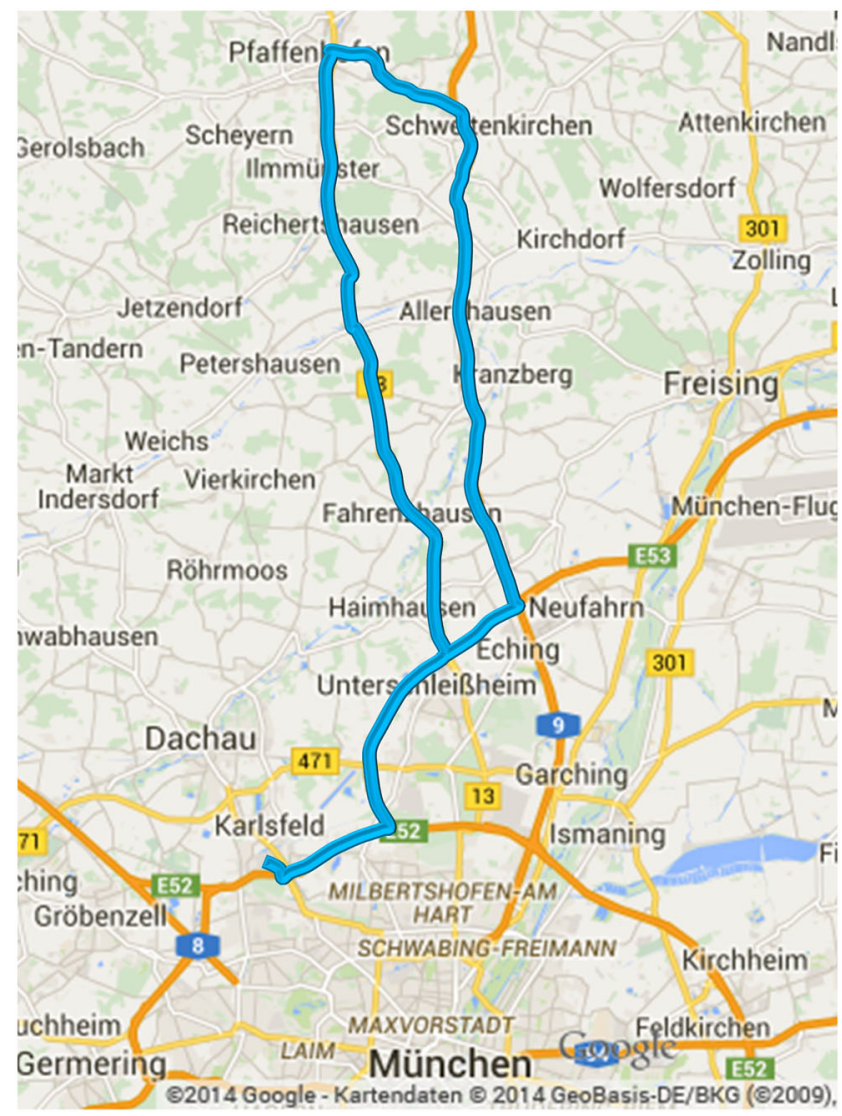

Fig. 8 Test track north of Munich 
Table 2 Average frequency of driving advice per trip on the test track for the category driving style

\begin{tabular}{ll}
\hline Driving advice & Avg. freq. per trip \\
\hline Reduce travel speed below $85 \mathrm{~km} / \mathrm{h}$ & 4.2 \\
$\begin{array}{l}\text { Maintain sufficient headway distance } \\
\quad \text { to preceding vehicles }\end{array}$ & 0.0 \\
$\begin{array}{l}\text { Maintain uniform velocity by using } \\
\text { cruise control and speed limiter }\end{array}$ & 6.3 \\
\hline
\end{tabular}

style leads to sufficient headway distance and thus to less relevant situations. In addition, on curvy road sections the detection range of the radar sensor and driver are equally limited. On straight road sections, drivers are able to perceive preceding vehicles prior to the radar sensor.

The real-world field tests demonstrate the technical feasibility to detect consumption relevant situations in real-world scenarios and that the driving advice leads to a more efficient driving style. Feedback of expert drivers gives a first indication of drivability which is evaluated more detailed in the driving simulator experiment.

\subsection{Driving simulator experiment}

In order to evaluate the concept of ViDCo and its efficacy, a driving simulator experiment was conducted. The methods of the experiment and the results of the objective measures are reported in detail by Daun et al. [11].

\subsubsection{Overview of the driving simulator experiment}

ViDCo's efficacy and aspects of driving behavior were evaluated by making use of a dynamic driving simulator. Participants were assigned to one of two groups: comparison group or experimental group. While both groups performed four runs on four tracks, only subjects of the experimental group were supported by ViDCo on the third run. $N=40$ datasets ( 20 per group) were available for the analysis of the results. The functionalities output interval adaptation and refusal detection of the filtering and prioritization module were deactivated during the experiment as they were expected to negatively affect comparability (Section 5.1.3).

Table 3 Average frequency of driving advice per trip on the test track for the category operational level

\begin{tabular}{ll}
\hline Driving advice & Avg. freq. per trip \\
\hline Avoid kick down & 1.0 \\
Accelerate at high engine torque & 1.8 \\
Decelerate using wear-free braking systems & 3.8 \\
Stall engine at long idling phases & 0.3 \\
\hline
\end{tabular}

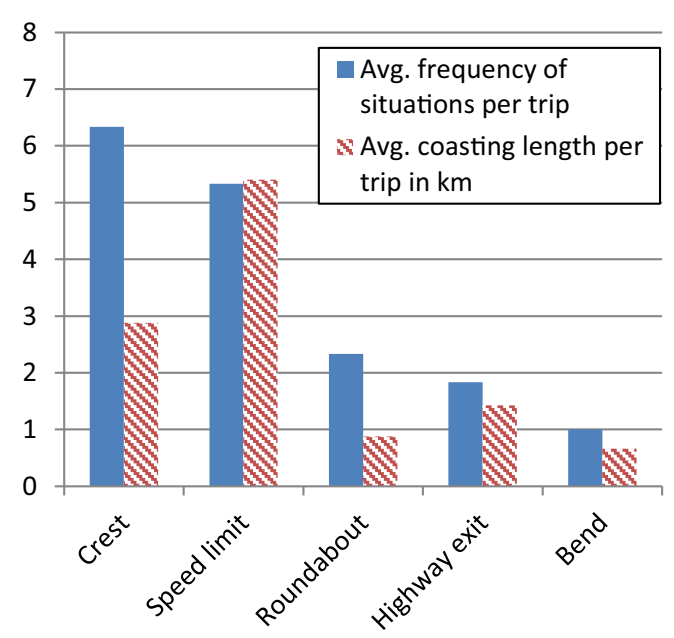

Fig. 9 Average frequency of anticipatory driving situations and corresponding coasting lengths on test track

The experiment proved that ViDCo's concept is capable of reducing fuel consumption significantly. Furthermore, the results indicate that drivers - at least in the short term-adapt driving advice of the system and therefore drive more efficiently without the EDAS after having been exposed to it (learning effect due to system experience). Both, system efficacy as well as the positive learning effect, were shown by means of a regression analysis of a linear mixed model (LMM). In this regression model, EDAS Usage and System Experience served as predictors (among three other predictors) on the regressand Average Fuel Consumption.

\subsubsection{Survey methods}

Several surveys were conducted during the experiment. Some of the surveys' questionnaires were designed to evaluate the design objectives system safety, user acceptance and system impact on learning. As an exposure to the system is indispensable in order to evaluate these aspects, the relevant questionnaires were only asked to subjects of the experimental group $(n=20)$.

System safety is a necessity before introducing an IVIS to the market. System safety is evaluated in the context of two explorative questionnaires (EQ 1 and EQ 2). These questionnaires mainly contain items evaluating aspects of user acceptance. EQ 1 consists of 12 items, EQ 2 of 15 items. Items are selected from multiple sources ([38, 39], and own design). Seven of the 27 items ask questions regarding distraction and disturbance due to the EDAS and therefore provide a first assessment of system safety. The first of the two questionnaires is deployed after the system run (run 3) following the after-measurement of the SAS. The second questionnaire (15 items) is used as part of a survey which is conducted after all four runs.

Emphasis is put on the evaluation of user acceptance in this early stage of the development process. If ViDCo and its 
concept were not accepted, at worst it would not yield any improvements of fuel efficiency. In this case, the concept would need to be re-designed to a great extent.

In order to analyze user acceptance, the System Acceptance Scale (SAS) of van der Laan et al. is used [40]. The English version of this scale consisting of nine items was translated into German. The before-measurement was performed after describing the EDAS as follows:

"Imagine a new driver assistance system is installed in your truck. The system can help you to drive more fuel efficiently. The system provides you with instructions during certain situations on how to adjust your driving style. Please specify what you would feel about such a system?"

Afterwards the subjects perform the system run (run 3), before conducting the after-measurement of the SAS (System Acceptance Scale). The after-measurement represents the actual assessment of the Virtual Driving Coach with regard to system acceptance.

A straightforward yes-no question is asked to obtain a selfassessment of the subjects, whether they believe they learned anything from ViDCo. We call this the participants' judgment of learning.

\subsubsection{Methods of LMM refitting}

In order to analyze whether the results of the survey with regard to system acceptance and the self-reported judgment of learning help to explain parts of the variances for the average fuel consumption, the LMM is refitted with data of the survey. The refittings are done by replacing the original variable System Experience either by the SAS scores or Judgment of Learning. Other explanatory variables of the original model remain unchanged. Evaluation of the quality of the model is done by fitting the model with a maximum loglikelihood (ML) approach and analyzing the corrected Akaike information criterion $(A I C c)$ [41, 42]. For the estimation of the fixed-effect values regarding the specific predictors, their $\mathrm{t}$ and $\mathrm{p}$-values, the restricted maximum log-likelihood (REML) method is used.

\subsubsection{Results}

As there is no control condition existing for the evaluation of EQ 1 and EQ 2, the results of the items regarding system safety are analyzed qualitatively. As illustrated in Fig. 10, the overall rating of the system is positive ( $M$ from 1.10 to 2.15 on a 5 -point Likert scale, with 1 representing a positive and 5 a negative rating).

The results of the SAS questionnaire's before- and aftermeasurement are presented in Table 4. For both measurements (before and after) as well as for both scales (Usefulness and Satisfying) the values of Cronbach's $\alpha$ indicate a high internal consistency with $\alpha$ coefficients ranging from 0.89 to 0.93 . Usefulness and Satisfying Scale improve both from the before to the after measurement. While a paired-samples t-test indicates a significant before-after difference for the Satisfying
Fig. 10 Results of the seven items of EQ 1 and EQ 2 asking for aspects of system safety. The scales of the two items labbeled with * are reversed for comparison reasons. Scale: "does not apply" $\triangleq 1$ (positive rating), "undecided" $\triangleq 3$ (neutral rating), "does apply" $\triangleq 5$ (negative rating). Items are translated from German.

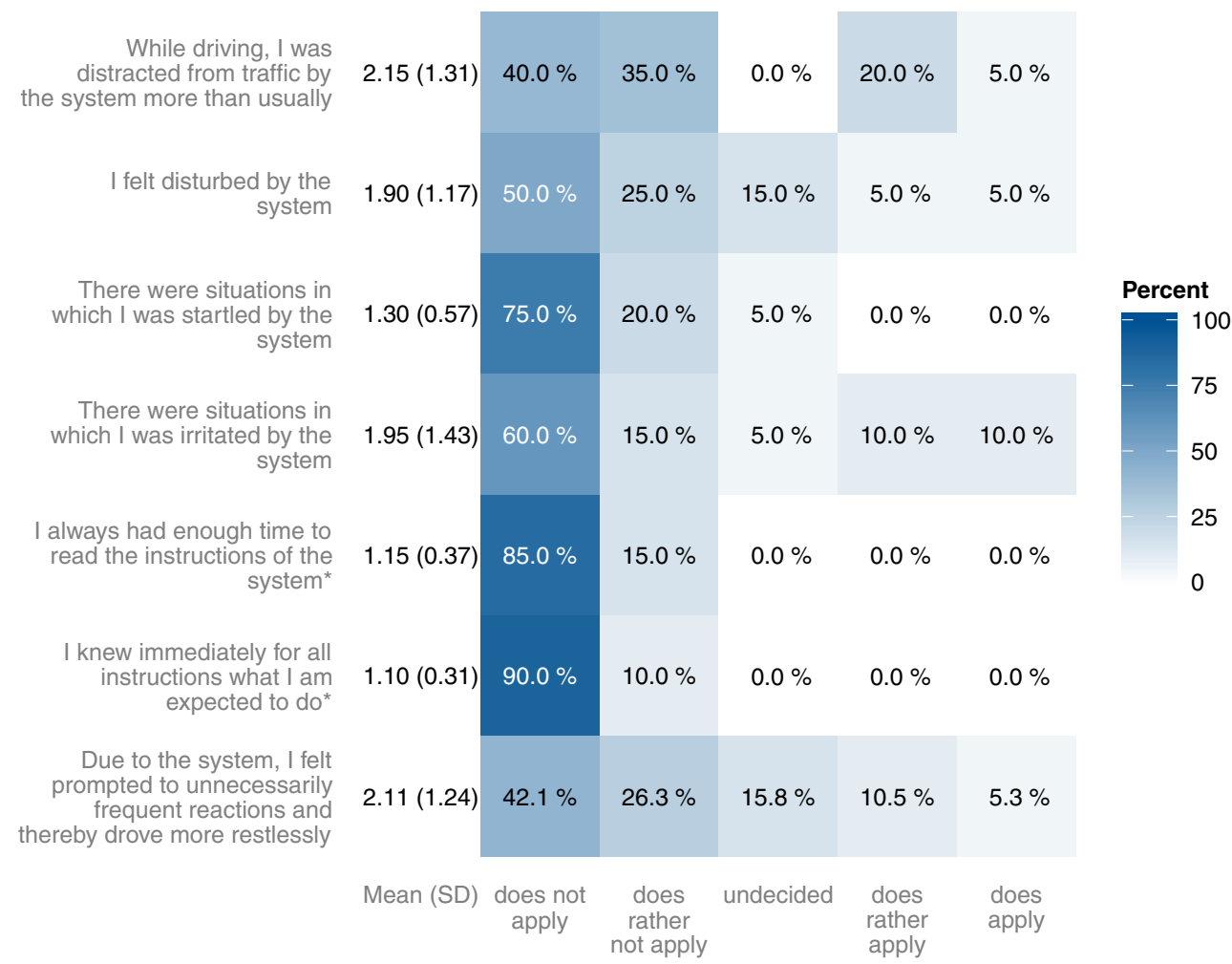


Table 4 Results of the SAS questionnaire

\begin{tabular}{|c|c|c|c|c|c|c|c|c|c|c|c|}
\hline & \multirow[b]{2}{*}{$\mathrm{n}$} & \multicolumn{5}{|c|}{ Usefulness scale } & \multicolumn{5}{|c|}{ Satisfying scale } \\
\hline & & mean & median & SD & $\min$ & $\max$ & mean & median & $\mathrm{SD}$ & $\min$ & $\max$ \\
\hline Before & 20 & 0.68 & 0.90 & 1.00 & -2.00 & 2.00 & -0.11 & -0.12 & 0.95 & -2.00 & 1.75 \\
\hline After & 20 & 0.94 & 1.30 & 0.98 & -1.60 & 2.00 & 0.49 & 0.88 & 1.17 & -2.00 & 2.00 \\
\hline
\end{tabular}

Scale $(t(19)=2.875, p=0.01)$, the difference of the Usefulness Scale is statistically not significant $(t(19)=1.407, p=0.18)$.

14 subjects out of the 20 participants of the system group answered with "yes" to the question whether they believe they have learned anything from the system while six truck drivers answered in the negative. Figure 11 shows a boxplot/beanplot comparison of the combined SAS over these judgments of learning. The combined SAS is the arithmetic mean of the Usefulness and Satisfying Scale. Each of the two scales alone, Usefulness Scale and Satisfying Scale, leads to similar results as the combined SAS of Fig. 11. However, the combined SAS is able to improve the LMM quality of the refitting better then Usefulness Scale and Satisfying Scale.

The higher overall SAS rating for the subjects answering with "yes" $(M=1.21, S D=0.49)$ is statistically significant compared to the scores for "no" $(M=-0.44, S D=0.95)$. This can be shown by means of an independent-samples t-test $(t(6.2)=4.019, p=0.007)$.

Table 5 contains the results of the original model fitting of the linear mixed model (LMM) [11] as well as two refittings regarding the predictor System Experience. When replacing System Experience by $S A S$ scores, model quality is improved (as $A I C c$ becomes smaller). The original model has a probability of $\exp ((658.3-659.7) / 2)=0.50$ compared to the refitted model to minimize the information loss [42, p. 74]. However, this improvement is less strong then the one using Judgment

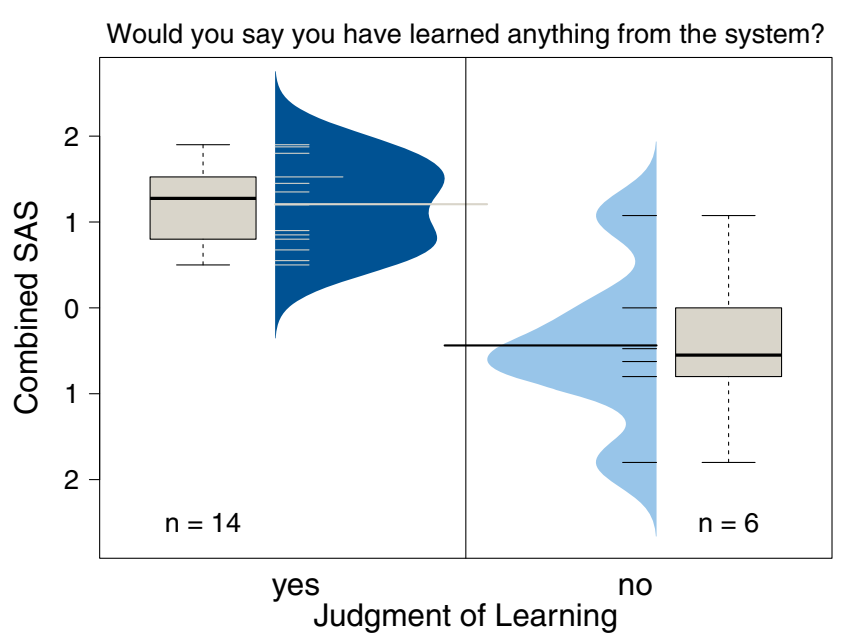

Fig. 11 Combined SAS over the subjects' judgment of learning due to EDAS usage of Learning as predictor. In this case the likelihood of the original model is reduced to not even 0.12 .

Analyzing the estimations of the fixed-effect $\beta$, the original model assesses the learning effect due to System Experience a fuel consumption reduction of $-1.04 \mathrm{~L} /$ $100 \mathrm{~km}$ or $-2.53 \%$ compared to a run without EDAS (run 2) [11]. Using the SAS scores as predictor suggest an average fuel consumption reduction of $1.21 \cdot(-0.90)$ $\mathrm{L} / 100 \mathrm{~km}=-1.09 \mathrm{~L} / 100 \mathrm{~km}$ or $-2.67 \%$ for those subjects answering with "yes" on the judgment of learning and an increase of $0.4 \mathrm{~L} / 100 \mathrm{~km}(0.97 \%)$ for the subjects answering in the negative. When a positive learning effect is only considered for those participants stating they have learned something by the system (Judgment of Learning), fuel consumption is reduced by $-1.64 \mathrm{~L} / 100 \mathrm{~km}$ or $-4.01 \%$.

One might think system acceptance ought to be a better predictor for the variance in fuel consumption of the system run (run 3 ) instead of the after-system run. However, when replacing EDAS Usage in the original model with the results of the SAS model, quality decreases sharply. In this case, the best fit is achieved by means of the Usefulness Scale (compared to Satisfying Scale and combined SAS). However, even this best fit is less than 0.001 times as likely as the original model.

\section{Discussion and conclusion}

The real-world field test proved the technical feasibility of a predictive eco-driving assistance system. Especially digital maps increase drivers' perception and lead to an improved anticipatory driving style.

Table 5 Results of different LMM predictors for the fixed-effect on run 4. Average fuel consumption is the response variable. System experience is the predictor of the original model [11]. Other predictors of the original model remain unchanged

\begin{tabular}{llllll}
\hline & $\beta$ & $\mathrm{DF}$ & $\mathrm{t}$ & $\mathrm{p}$ & $\mathrm{AICc}$ \\
\hline System experience & -1.04 & 98 & -2.077 & 0.040 & 659.7 \\
SAS scores & -0.90 & 98 & -2.397 & 0.018 & 658.3 \\
Judgment of learning & -1.64 & 98 & -2.943 & 0.004 & 655.4 \\
\hline
\end{tabular}

$\beta$ in $\mathrm{L} / 100 \mathrm{~km}$ for System experience and Jdg. of learning

$\beta$ in $\mathrm{L} / 100 \mathrm{~km}$ per SAS score for SAS scores

$\beta, \mathrm{t}, \mathrm{p}$ fitted by REML, AICc fitted by ML 
The first assessment of ViDCo's system safety can be regarded positive in total (Fig. 10). However, answers to specific items of the questionnaire call for attention. One quarter of the participants stated that they were distracted by the system more than usually. As there are no control conditions for EQ 1 and EQ 2, a quantitative assessment of this "more than usually" seems to be difficult. Therefore, in future studies which focus specifically on the evaluation of system safety, a control condition with a well-established advanced driver assistance system (ADAS) or in-vehicle information system (IVIS) could be introduced. Other solutions include the usage of validated and standardized questionnaires (e.g., NASATLX [43]) or the measurement of drivers' eye glance behavior [44].

The Virtual Driving Coach's results of the driving simulator experiment with respect to system acceptance scale (SAS) seem promising. This applies also in comparison to other systems' scores. In Fig. 12, ViDCo is benchmarked with eight other systems' Usefulness and Satisfying Scales of the SAS after measurement. ViDCo achieves scores comparable to an intelligent cruise control [40], a curve-speed warning system [45], a forward collision warning system [45], and, most satisfactory, another EDAS [46].

Even though this first assessment of system acceptance can be rated positively, the significance of these results is restricted. The main reason for this restriction is the lack of knowledge regarding the relationship between short-term acceptance and long-term acceptance of ADAS and IVIS. Adell's evaluation of two intelligent speed adaptation systems lead her to the conclusion that drivers need more than 1 month to adapt to a system without being able to specify the end of this adaptation process $[47$, p. 58].

Very remarkable are the results of the subjects' judgment of learning due to the EDAS. While this judgment alone does not leave much space for interpretation, its relationship with other aspects of the experiment does. There seems to be a very clear relationship of this judgment with system acceptance (Fig. 11). This relationship, however, does not say anything about the causality. Furthermore there is the possibility that the question about the judgment of learning and the SAS questionnaire inadvertently measure the same construct (operational confounding).

On the supposition that no operational confounding applies, we believe the most likely explanation of the causality for a system which aims on implicit transfer of knowledge, as ViDCo does, is as follows: system acceptance is a prerequisite of learning. Therefore, only if the system is accepted by the users are they open for adapting their behavior according to advice of the system. For the Virtual Driving Coach, this adaptation translates into a reduction of fuel consumption which can be interpreted as a positive learning effect.

We support this theory since the self-reported judgments of learning serve as much better predictor of the fuelconsumption reduction between run 2 and run 4 of the experimental group than the results of the SAS questionnaire (Table 5). Firstly, this indicates that the self-reported judgments of learning are plausible since these judgments help to explain more of the variance of the measured data. Secondly, these results might be interpreted in such way, that it appears system acceptance is "further" away from the actual outcome of a positive learning effect: a reduction in fuel consumption.

On the one hand we cannot rule out the possibility of operational confounding. On the other hand the explanatory power of the questionnaires and the model refitting might very well be limited due to the sample size of $n=20$. Thus, the results of the model refitting cannot be regarded as proof for our hypothesis about the causality between system acceptance and learning. However, they represent a first positive indication. In order to fully understand the relationship between system acceptance and the learning effect of systems aiming at the implicit transfer of knowledge, more research is needed. Therefore, future studies might focus on the causality of acceptance and learning. This includes showing that the selfreported learning effect and system acceptance can indeed be measured as two independent, latent constructs.

Furthermore and similar to the restrictions of the results with regard to system acceptance, the observed effects on learning are of a short-term nature. For a lasting improvement
Fig. 12 Usefulness scale over satisfying scale for different systems compared to the Virtual Driving Coach (with data from $[40,45,46])$

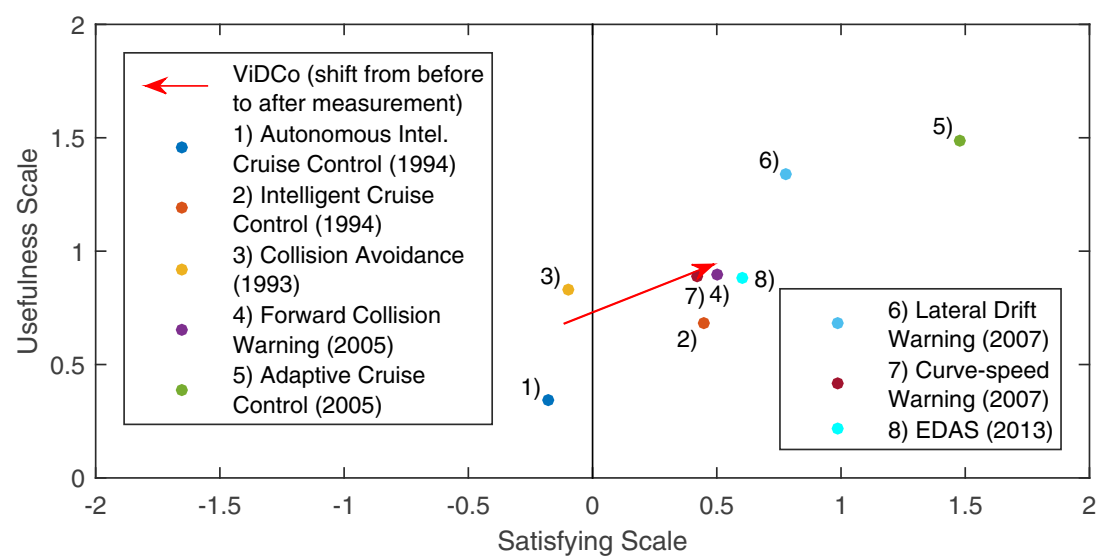


of fuel efficiency however, the long-term effects are of interest. In order to analyze the long-term effects, costly longitudinal studies represent the means of choice.

Acknowledgments This research was funded by the German Federal Ministry for Economic Affairs and Energy (BMWi) within the joint project "ViFa - Virtueller Fahrtrainer - Entwicklung eines virtuellen Fahrtrainers zur Unterstützung einer verbrauchs- und verschleißoptimierten Fahrweise”.

Open Access This article is distributed under the terms of the Creative Commons Attribution 4.0 International License (http:// creativecommons.org/licenses/by/4.0/), which permits unrestricted use, distribution, and reproduction in any medium, provided you give appropriate credit to the original author(s) and the source, provide a link to the Creative Commons license, and indicate if changes were made.

\section{References}

1. VDA (2008) Das Nutzfahrzeug - umweltfreundlich und effizient, 2nd edn. Frankfurt am Main

2. Geiler M, Kerwien H (2008) Wirksamkeitsstudie zu einem training ökonomischen fahrens. Verkehrssicherheit 54 Nr. 3: 138-145

3. Wåhlberg A (2007) Long-term effects of training in economical driving: fuel consumption, accidents, driver acceleration behavior and technical feedback. Int J Ind Ergon 37(4):333-343

4. Bundesverband Güterverkehr Logistik und Entsorgung (2013) Kostenentwicklung im güterkraftverkehr: kostenstruktur nationaler fernverkehr

5. Scania (2014) Scania Driver Support. http://www.scania.de/trucks/ safety-driver-support/driver-support-systems/scania_fahrer_ecomodul/

6. Daimler (2011) FleetBoard inside: telematics as standard on the new actros. Press Information, p 3

7. Logistik V'Info (2010) Ergebnisbroschüre Logistik-V'Info: verkehrsinformationen für dynamische transporte: mehr leistung für die logistik - entlastung für umwelt und infrastruktur. 2010

8. Lindhuber S, Popp C, Schulze C (2010) Driver assistance system for driver assistance for consumption controlled driving (US20120078496 A1). Accessed 19 Mar 2014

9. Dorrer C (2004) Effizienzbestimmung von fahrweisen und fahrerassistenz zur reduzierung des kraftstoffverbrauchs unter nutzung telematischer informationen. doctoral thesis, Stuttgart

10. Rommerskirchen C, Helmbrecht M, Bengler K (2014) The impact of an anticipatory eco-driver assistant system in different complex driving situations on the driver behavior. IEEE Intell Transp Syst Mag 6(2):45-56. doi:10.1109/MITS.2014.2307078

11. Daun TJ, Braun DG, Frank C et al (2013) Evaluation of driving behavior and the efficacy of a predictive eco-driving assistance system for heavy commercial vehicles in a driving simulator experiment. In: 2013 16th International IEEE Conference on Intelligent Transportation Systems - (ITSC 2013), pp 2379-2386

12. Domina R (2009) Wirtschaftlich fahren: handbuch für fahrer, 1. Aufl. berufskraftfahrer-weiterbildung LKW. Huss, München

13. Department for Transport (2009) The fuel efficient truck drivers' handbook: freight best practice pocket guide

14. MAN Truck \& Bus AG (2008) The MAN driver training, München

15. Heyes D, Daun T, Dörner K et al. (2014) Verbundprojekt: ViFa virtueller fahrtrainer: entwicklung eines virtuellen fahrtrainers zur unterstützung einer verbrauchs- und verschleissoptimierten fahrweise. Final report, Köln
16. Heyes D, Hipp E, Zimmermann A et al (2012) Systematische bewertung des fahrereinflusses auf die transporteffizienz von nutzfahrzeugen. 5. tagung fahrerassistenz, München

17. Fastenmeier W (1995) Autofahrer und Verkehrssituation: neue wege zur bewertung von sicherheit und zuverlässigkeit moderner strassenverkehrssysteme. Mensch-fahrzeug-umwelt, Bd. 33, TÜV Rheinland, Köln: 27ff

18. Zeitzen F Der kleine unterschied: tempo 82 gegen 89. lastauto omnibus 10/2010: 10-15

19. Cerchez S (2011) Quer durch Europa. lastauto omnibus 09/2011

20. Grünig G (2011) MAN TGX efficient line: trucker supertest. Trucker $7 / 2011$

21. Huber M (2008) Verfahren zum betreiben eines fahrzeuges, insbesondere eines nutzfahrzeuges, steuer- und/oder auswerteeinrichtung, fahrerassistenzsystem für ein nutzfahrzeug sowie nutzfahrzeug (DE 102008023135 A1)

22. Kock P, Gnatzig S, Passenberg B et al (2008) Improved cruise control for heavy trucks using combined heuristic and predictive control. IEEE Int Conf Control Appl

23. Fröberg A, Hellström E, Nielsen L (2006) Explicit fuel optimal speed profiles for heavy trucks on a set of topographic road profiles. SAE Tech Pap Ser 2006-01-1071

24. de Waard D (1996) The measurement of drivers' mental workload. $\mathrm{PhD}$ thesis, Rijksuniversiteit Groningen

25. Cain B (2007) A review of the mental workload literature. In: NATO Science and Technology Organization (ed) Virtual environments for intuitive human-system interaction: human factors considerations in the design, use, and evaluation of AMVE-technology

26. Hipp E, Heyes D, Seitz M et al (2013) Beanspruchungsadaptive fahrerunterstützung - der weg zum sicheren und effizienten fahren

27. Prevent (2009) RESPONSE 3: code of practice for the design and evaluation of ADAS

28. International Organization for Standardization (2013) Road vehicles - ergonomic aspects of transport information and control systems - dialogue management principles and compliance procedures 13.180; 43.040 .15 (ISO 15005:2002)

29. Dillon A, Morris MG (1996) User acceptance of new information technology: theories and models. Ann Rev Inf Sci Technol 31:3-32

30. Skinner BF (1953) Science and human behavior. A Free Press paperback, Macmillan, New York

31. Frensch PA (1998) One concept, multiple meanings: how to define the concept of "implicit learning". In: Stadler MA, Frensch PA (eds) Handbook of implicit learning. Sage Publications, Thousand Oaks, pp 47-104

32. Voort MC van der (2001) Design and evaluation of a new fuelefficiency support tool. Dissertation, Universiteit Twente

33. Balota DA, Duchek JM, Logan JM (2007) Is expanded retrieval practice a superior form of spaced retrieval? A critical review of the extant literature. In: Nairne JS (ed) The foundations of remembering: essays in honor of Henry L. Roediger, III. Psychology Press, New York, pp 83-105

34. Maurer M, Winner H (2013) Automotive systems engineering. Springer Berlin Heidelberg, Berlin, Heidelberg

35. Kraftfahrt-Bundesamt (2013) Fahrzeugzulassungen. Statistische mitteilungen des kraftfahrt-bundesamtes FZ 26,. www.kba.de. Accessed 26 Sep 2013

36. Ress C, Etemad A, Kuck D et al (2006) Electronic horizon supporting ADAS applications with predictive map data. 13th ITS World Congress, London

37. Moebus M, Wagner M, Jacobs M et al (2011) Digitale karten als vorausschauende sensoren für fahrerassistenzsysteme. VDE/VDI AmE - Automotive meets Electronics - 2. GMM-Fachtagung, Dortmund

38. Mohra HR (2013) Fahrerassistenzsystem zur unterstützung einer energieeffizienten fahrweise. doctoral thesis, Technische Universität München 
39. Assmann E (1985) Untersuchung über den Einfluss einer bremsweganzeige auf das fahrverhalten. Dissertation, Technische Universität München

40. van der Laan JD, Heino A, de Waard D (1997) A simple procedure for the assessment of acceptance of advanced transport telematics. Transp Res C Emerg Technol 5(1):1-10. doi:10.1016/S0968090X(96)00025-3

41. Zuur AF, Ieno EN, Walker N et al (2009) Mixed effects models and extensions in ecology with R. Statistics for biology and health. Springer Science+Business Media, LLC, New York

42. Burnham KP, Anderson DR (2002) Model selection and multimodel inference: a practical information-theoretic approach, 2nd edn. Springer, New York

43. Hart SG, Staveland LE (1988) Development of NASA-TLX (Task Load Index): results of empirical and theoretical research. In: Human Mental Workload, vol 52. Elsevier, pp 139-183
44. SAE International (2000) Definitions and experimental measures related to the specification of driver visual behavior using video based techniques (SAE J 2396)

45. Sayer JR, LeBlanc DJ, Mefford ML et al (2007) Field test results of a road departure crash warning system: driver acceptance, perceived utility and willingness to purchase. In: Proceedings of the 4th International Driving Symposium on Human Factors in Driver Assessment, Training, and Vehicle Design: Driving assessment 2007. University of Iowa, Public Policy Center, Iowa City, Iowa

46. Staubach M, Schebitz N, Krehle T et al (2013) User acceptance of an eco-driving support system. Proceedings - 9th ITS European Congress, Dublin

47. Adell E (2009) Driver experience and acceptance of driver support systems: a case of speed adaptation. Doctoral Thesis, Lunds Universitet 